\title{
Entailment, assertion, and textual coherence: the case of almost and barely*
}

PATRÍCIA AMARAL

\section{Abstract}

This article contributes to the study of approximative adverbs almost and barely by providing psycholinguistic evidence for the asymmetry of their meaning components. The experiments reported are discussed against the background of a set of tests targeting the theoretical status of the meaning components. The first experiment addresses the role played by each meaning component in textual coherence, whereas the second experiment addresses the interpretation in isolation of a sentence containing an approximative adverb. The results argue for a pragmatic difference in the role of the meaning components, along the lines of Horn's (2002) proposal, pertaining to the way in which the implications of approximative adverbs contribute to context update.

\section{Introduction}

It has long been noticed that the contribution of a lexical item to the meaning of a sentence (e.g., even, only, already) may yield more than one entailment (Löbner 1989; Kay 1990; König 1991; Horn 2002; among others). This paper focuses on the relation between this phenomenon and textual coherence. In particular, this paper adopts an experimental approach to the behavior of the different entailments contributed by the meaning of a lexical item. The focus is on the meaning of English "approximative adverbs" (henceforth AAs) almost and barely.

The semantic and pragmatic properties of this pair of adverbs have been the subject of much debate in the literature, in particular pertaining to the theoretical status of each of their meaning components (Ducrot 1972; Anscombre and Ducrot 1983; Klein 1998; Sevi 1998; Horn 2002; Schwenter 2002). The current study contributes to this line of research by providing psycholinguistic evidence that the entailments of an AA are 
"asymmetric" in that they play different roles in interpretation, by either having a bearing on textual coherence, or on the determination of the truth conditions of a sentence containing an AA.

The outline of the paper is as follows. In Section 2, I present the theoretical background pertaining to the "Conjunctive Analysis" of AAs and discuss the status of each of the meaning components. In Section 3, I introduce the present study and describe the two experiments conducted. Section 4 provides a discussion of the results and Section 5 offers concluding remarks.

\section{Background: the "Conjunctive Analysis"}

In the literature, the meaning of AAs has been accounted for by a "Conjunctive Analysis", i.e., as the conjunction of two propositions that instantiate two meaning components (Ducrot 1972; Sadock 1981; Hitzeman 1992; Rapp and Von Stechow 1999; Sevi 1998; Horn 2002; Schwenter 2002). Following Sevi (1998) and Horn (2002), these will be called the proximal component and the polar component, as exemplified in (1) and (2) for almost and barely, respectively:

(1) John almost missed the train.

$\left(1^{\prime}\right)$ John came close to missing the train. [Proximal component]

$\left(1^{\prime \prime}\right)$ John did not miss the train. [Polar component]

(2) John barely missed the train.

$\left(2^{\prime}\right) \quad J o h n$ came close to not missing the train. [Proximal component]

$\left(2^{\prime \prime}\right)$ John missed the train. [Polar component]

The exact nature of the intuitive notion of closeness, paraphrased in $\left(1^{\prime}\right)$ and $\left(2^{\prime}\right)$, is hard to grasp. On an intensional approach, this notion is captured through a relation of similarity between possible worlds (Sadock 1981; Rapp and Von Stechow 1999) or more generally through a relation of closeness between indices of contextual coordinates (Sevi 1998; Horn 2002). The truth conditions of each adverb are given in (3) from Sevi (1998):

(3) Let A be a formula, let I be a discrete set, and let $<$ be a threeplace relation such that for every $\mathrm{i}^{*} \in \mathrm{I},<_{\mathrm{i}^{*}}$ is a strict partial order on $I\left(i_{1}<i^{*} i_{2}\right.$ is read as $i_{1}$ is closer to $i^{*}$ than $\left.i_{2}\right)$.

$[[\operatorname{almostA}]]^{i *}=1$ iff $[[\mathrm{A}]]^{\mathrm{i}^{*}}=0$ and there is an $\mathrm{i}^{\prime}$, s.t. for any $\mathrm{i}^{\prime \prime}$, $\mathrm{i}^{\prime}<\mathrm{i}^{*} \mathrm{i}^{\prime \prime}$, and $[[\mathrm{A}]]^{\mathrm{j}^{\prime}}=1$

$[[\text { barelyA }]]^{i^{*}}=1$ iff $[[\mathrm{A}]]^{\mathrm{i}^{*}}=1$ and there is an $\mathrm{i}^{\prime}$, s.t. for any $\mathrm{i}^{\prime \prime}$, $\mathrm{i}^{\prime}<_{\mathrm{i}^{*}} \mathrm{i}^{\prime \prime}$, and $[[\mathrm{A}]]^{\mathrm{i}^{\prime}}=0$ (Sevi 1998: 65, under [8]) 
Two main consequences follow from these truth conditions. First of all, according to (3) the adverbs are defined as the inner negation of each other, i.e., almost not is predicted to be equivalent to barely and barely not is predicted to be equivalent to almost. Second, the contribution of each adverb is analyzed in terms of two assertions (a negative and a positive one) of equal status.

However, there seems to be a difference between the two components: intuitively, the point of uttering (1) or (2) is to say something about the closeness to a certain state of affairs being the case, and not to state that John did not miss the train (in [1]) or that he did, in (2). In the next section, I will refer to this problem as the asymmetry of the meaning components of AAs (following Horn 2002). Although Sevi acknowledges that the two propositions are not equally "important" (Sevi 1998: 66) for the interpretation of each adverb, he does not specify a way in which this difference should be modelled.

Note also that under the Conjunctive Analysis the proximal component of each adverb actually conflates both a closeness relation and a positive or a negative clause: almost $P$ "also asserts $P$ relative to some element i" (Sevi 1998: 66), and barely $P$ "also asserts not $P$ relative to some element $i^{\prime \prime}$ (Sevi 1998: 66). In the aspectual domain, one could conceive of the proximal component in terms of the selection of a polar value in a transition between two states of affairs of opposite polarity. ${ }^{1}$ Whereas the meaning of both adverbs makes reference to a polar switch from negative to positive, i.e., from not missing the train to missing the train, ${ }^{2}$ in the case of almost, this transition is oriented toward the positive area, while in the case of barely the transition is oriented toward the negative area.

\subsection{The status of the meaning components}

Crosslinguistically, there is robust evidence for the asymmetric status of the two components (Anscombre and Ducrot 1983; Li 1976; Horn 2002; Schwenter 2002; Nouwen 2006), in particular pertaining to the "backgrounded" (Sevi 1998: 32) nature of the polar component. For example, a yes/no question is interpreted as inquiring about the proximal component rather than about the polar component (Schwenter 2002). Hence, $\left(4^{\prime}\right)$ is a plausible elaboration on B's response in (4), but (4") seems less felicitous:

A: Did John almost miss the train?

B: Yes ( = he came close to missing the train and he did not miss the train) 
$\left(4^{\prime}\right) \quad$ Yes, he caught it just in the nick of time.

$\left(4^{\prime \prime}\right) \quad$ \#Yes, he managed to catch it.

Denying the polar component requires the use of metalinguistic negation (in the sense of Horn 1985), as shown by the contrast between the possible answers of $\mathrm{B}$ in $\left(5^{\prime}\right)$ and $\left(5^{\prime \prime}\right)$ :

(5) B: No. (= he did not get close to missing the train; $\neq$ he missed the train)

$\left(5^{\prime}\right)$ B: No, he didn't. In fact, he was there a full ten minutes before it left.

(5") B: No, he didn't ALMOST miss the train. He DID miss it. He showed up after it had already pulled away from the platform. ${ }^{3}$

Crucially, descriptive negation does not affect the polar component; (5) is generally not interpreted as entailing that John missed the train, which would be predicted as a result of double negation, i.e., $\sim(\sim$ miss_the_train $(\mathrm{j}))$.

Furthermore, evaluative adverbs express an evaluation of the truth of the proximal component, not of the polar component (Nouwen 2006):

(6) Fortunately, Peter can barely read (so he couldn't fully understand the insults addressed to him / \#so I can write him a note).

In (6), what is evaluated as fortunate is not the fact that Peter can read, but rather the fact that Peter's reading skills are unsatisfactory, as shown by the felicitous continuation.

Moreover, in (7) the causal clause elaborates on the proximal component, not on the polar component (Ziegeler 2000; Horn 2002: 58). This can be shown by comparing the infelicity of $\left(7^{\prime}\right)$ against the felicitous version in $\left(7^{\prime \prime}\right)$ :

(7) I almost cancelled because I was ill.

(7') \#I almost cancelled because I would have felt too guilty.

$\left(7^{\prime}\right)$ I didn't cancel because I would have felt too guilty.

In sentences with the negative polarity item (NPI) let alone licensed by barely, the polar component cannot be interpreted as obtaining in the second conjunct (Fillmore et al. 1988: 529). Hence, the adequate paraphrase of (8) is (10), not (9):

(8) He barely reached Denver let alone Chicago.

(9) He barely reached Denver; a fortiori he barely reached Chicago.

(10) He barely reached Denver; a fortiori he did NOT reach Chicago.

Ducrot (1972) and Anscombre and Ducrot (1983), in their analysis of the meaning of presque and à peine (French counterparts of 'almost' and 
'barely', respectively) argue that the two adverbs have opposing scalar orientations, i.e., that they induce argumentative scales of opposite orientation. ${ }^{4}$ The "positive argumentative orientation" of almost and the "negative argumentative orientation" of barely can be tested by comparing possible continuations of sentences containing AAs. What is crucial for our purposes is that these continuations build on the proximal component and not on the polar component, as shown by (11) and (12), from Anscombre and Ducrot (1983: 80):

(11) Il fait presque nuit, allume tes veilleuses/\#allume seulement tes veilleuses.

'It is almost night, turn your night lights on/\#turn only your night lights on.'

(12) Il fait à peine nuit, \#allume tes veilleuses/allume seulement tes veilleuses.

'It is barely night, \#turn your night lights on/turn only your night lights on.'

The proximal component of almost and barely contributes in two ways to constrain the range of contexts in which the adverbs may be felicitously used, as exemplified in (11) and (12). First, as pointed out in the previous section, the meaning of almost introduces a relation of closeness with respect to a positive state of affairs (in this case, being night), whereas barely introduces a relation of closeness to a negative state (not being night). In the former case, the nocturnal absence of light would provide a justification for the felicitous unqualified directive in (11), whereas the presence of some light, albeit dim, would be coherent with the sufficiency of lights that are considered weak on a scale of intensity. The scalar meaning of the exclusive focus adverb seulement 'only' in (11) and (12), as well as the lexical meaning of veilleuse (which is a weaker light than regular light $)^{5}$ constrains the felicitous continuations of the sentences with almost and barely. Examples (11) and (12) show that the orientation towards a positive or a negative state of affairs displayed by AAs relates to their scalar semantics and the related notion of "sufficiency" (cf. Hitzeman 1992; Amaral 2007), which goes beyond the scope of this paper.

The felicity patterns observed in (11) and (12) provide the counterpart, at the discourse level, of the causal connection at the sentence level, noted in (7) above, that also builds on the proximal component of the adverb.

Finally, a related puzzle is the licensing of NPIs. As pointed out by Horn (2002: 56), the distribution of NPIs runs against the polar component of the two adverbs:

(13) \#She almost \{budged/slept a wink/touched a drop/spoke to anyone\}. 
(14) She barely $\{$ budged/slept a wink/touched a drop/spoke to anyone\}.

Furthermore, experimental approaches that have investigated the meaning of almost and its bearing on textual inference (Lundquist and Jarvella 1994; Jarvella and Lundquist 1994) provide further evidence for the asymmetry of the meaning components of AAs. ${ }^{6}$ The authors argue that almost contributes a positive argumentative orientation (in the sense of Anscombre and Ducrot 1983) by licensing conclusions coherent with a high value on a contextually relevant scale. In reading and comprehension tasks involving anaphora resolution, the meaning of the adverb constrains the interpretation of the text in that it guides the inferences made about the discourse referents. These studies focused on the interpretation of texts describing competitions and the results achieved by different competitors. Subjects were asked to read sequences of two sentences. The first sentence contained the proper name of a participant in a competition and an expression describing his/her score, using either almost or only (e.g., Nichols obtained almost/only 129 points) and was followed by a sentence with an ambiguous definite description that could refer to either participant previously mentioned in the text (e.g., The red-haired Irish lad seemed to be leading). Then subjects were asked to identify the referent of the definite NP in the second sentence on the basis of the information provided by the first sentence, and hence identify the winner or the loser of the competition. Not only did the presence of the adverb have a disambiguating influence (in the determination of either a coreferential or a disjoint interpretation), but it also increased text comprehensibility in a significant way. This was assessed through the ratings assigned by subjects to texts in which the adverbs almost and only occurred, versus texts in which the scores of the competitors were provided with no modifier.

The data discussed in this section raise the question of the theoretical status that ought to be attributed to the polar component. Treating it as an assertion, in parallel to the proximal component, is hard to reconcile with the observations made above. A presuppositional account (e.g., Ducrot 1972) runs into problems because sentences containing AAs fail to pass the standard "family of sentences" tests for presupposition (Kadmon 2001; for a more thorough set of tests for presupposition and different types of non-asserted meanings, see the discussion in Roberts [submitted]). According to native speakers' intuitions, the polar component does not survive in examples like (15)-(20); it does not seem to be "taken for granted" in any of the sentences below in the same way that e.g., the presuppositions of a definite NP or of a factive verb are (regardless of whether one accounts for the triggering of these implications as being 
strictly conventional or context-dependent). In some cases the tests are not easy to apply, since the examples are anomalous or infelicitous, like (18).

(15) Did John almost miss the train?

(16) It is not true that John almost missed the train.

(17) Perhaps John almost missed the train.

(18) ?Did John barely miss the train?

(19) It is not true that John barely missed the train.

(20) Perhaps John barely missed the train.

Although the "family of sentences" test may not be totally reliable for presupposition status (see Kadmon 2001 for discussion), it remains to be determined how one could otherwise test for the presuppositional nature of the polar implication of an AA.

On the other hand, it seems hard to deny that the polar component is a conventionally triggered aspect of the meaning contributed by AAs; proponents of the conversational implicature account must face the problem, already noted in Sadock (1981), that the polar component is not cancellable. Hence, a sentence like (21) is either contradictory or else must be interpreted as a sort of corrective move of the speaker:

(21) \#John almost missed the train; in fact he did miss it.

Horn (2002) proposes that the asymmetry of the meaning components be conceived in terms of context update; only the proximal component is added to the common ground and hence presented as potentially controversial information. In other words, only the proximal component is asserted (in the sense of Stalnaker 1978), although both the proximal and the polar components are entailed: "Semantically entailed material that is outside the scope of the asserted, and hence potentially controversial, aspect of utterance meaning counts as ASSERTORICALLY INERT and hence as effectively transparent to NPI-licensing and related diagnostics of scalar orientation." (Horn 2002: 62)

The hypothesis to be pursued in this paper, following Horn, is that both components are entailed by AAs, but only the proximal component is asserted. This hypothesis, which pertains to the theoretical status of the meaning components, relates to the specific hypotheses tested in the two experiments. First, the positive component of almost and the negative component of barely (i.e., the proximal component in each case, the asserted content) should play a role in textual coherence, unlike the (merely entailed) polar component. Second, if the polar component is indeed part of the conventional meaning of AAs, it should play a role in the 
determination of the truth conditions of the sentence in which the adverb occurs, independently of contextual information, despite its "backgroundedness".

\section{The experiments}

The present study investigates whether there is psycholinguistic evidence for the theoretical distinction between the status of the two propositional components and in particular whether entailed information plays a different role in context update depending on its assertoric force.

Two experiments were conducted. The first experiment tested the role of each meaning component with respect to textual coherence. Since asserted information is the speaker's contribution to context update (i.e., how the sentence affects the conversational record), the coherent continuation is predicted to be the one that builds on the asserted component. The second experiment tested the role of each component when the sentence is interpreted in isolation, i.e., when subjects are directly asked about the truth conditions of the sentence. In this case, responses are predicted to be in accordance with entailed content (the invariant truthconditional content of the sentence), since the relation of the sentence with the context of utterance is not at issue.

The design of the present study builds on an analogy with research on quantifiers that denote vague quantities like few and most (Moxey and Sanford 1993, 1998; Paterson et al. 1998), which is reminiscent of some of the issues discussed above. In production and comprehension tasks, the meaning of quantifiers like $a$ few and few is differentiated by subjects in terms of the possible continuations that are considered to be felicitous:

(22) A few members of parliament were at the meeting. ${ }^{7}$

(23) Few members of parliament were at the meeting.

While (24) is considered by subjects as a felicitous continuation of (22), (25) is judged less acceptable as a continuation of (22) and is considered instead a more natural continuation of (23):

(24) They talked about the Education Bill.

(25) They were out with their secretaries instead.

According to Moxey and Sanford (1993), "positive" (e.g., a few, most) and "negative" (e.g., few, not many) quantifiers introduce a "focal bias" with respect to the set of entities which constitutes the antecedent of the anaphoric expression, in this case the pronoun they. Positive quantifiers favor reference to the set of which the predicate is true (i.e., the members 
of parliament who were at the meeting), called the "reference set" or "refset", as in (24). On the other hand, negative quantifiers favor reference to the set of which the predicate is false (i.e., the members of parliament who were not at the meeting), called the "complement set" or "compset", as in (25).

In the present study, a similar methodology is used in reading and judgment tasks to test the interpretation of sequences of sentences. The first sentence in the sequence contains an AA and the second sentence contains a connective that retrieves one of the meaning components of the AA. This contextual manipulation makes it possible to target each of the propositions entailed by the sentence that contains an AA, as exemplified in (26) and (27).

(26) John can almost swim. Therefore he'll enjoy a day at the pool with his friends. / \#Therefore he's afraid of drowning.

(27) John can barely swim. \#Therefore he'll enjoy a day at the pool with his friends. / Therefore he's afraid of drowning.

According to the theoretical assumptions presented at the end of Section 2, the hypothesis is that almost behaves like a "positive" quantifier in that it favors continuations coherent with the truth of the predicate over which it has scope (in accordance with the proximal component of the adverb in [1']), whereas barely licenses continuations coherent with the falsity of the predicate (in accordance with the proximal component paraphrased in $\left.\left[2^{\prime}\right]\right)$, and in this respect displays a behavior similar to that of "negative" quantifiers. Despite the fact that modification with almost entails the negation of the predicate, and modification with barely entails the truth of the predicate, the felicitous continuation in (28) and (29) is not the sentence that would coherently follow the respective polar component:

(28) John cannot swim. \#Therefore he'll enjoy a day at the pool with his friends. / Therefore he's afraid of drowning.

(29) John can swim. Therefore he'll enjoy a day at the pool with his friends. / \#Therefore he's afraid of drowning.

Such a comparison provides a more rigorous procedure to test the positive and the negative "argumentative orientation" of almost and barely, respectively, identified by Anscombre and Ducrot (cf. Horn 2002; Schwenter 2002).

\subsection{Design of the experiments}

Both experiments were designed as a $2 \times 2$ completely crossed factorial, with 4 lists in each experiment, in order to counterbalance possible 
confounding factors, e.g., length of the stimuli in words and word frequency. Each list comprised 20 critical items ( 5 per condition), and the same predicates were used in both experiments. In order to allow for a fair comparison, all the critical items included the modal verb can and an activity verb. Each list comprised 68 fillers, which included either activity verbs and a manner adverb (e.g., swims slowly) or a predicative nominal (e.g., is an experienced diver). The order of presentation of filler and critical items was pseudo-randomized. ${ }^{8}$ Each subject saw only one list and different subjects were used in the two experiments.

A total number of 96 subjects, undergraduate students at The Ohio State University, were tested (50 for Experiment 1, 46 for Experiment 2), of which the non-native speakers of English were excluded. The total number of subjects whose data were analyzed was 48 for Experiment 1 (12 subjects per list) and 40 for Experiment 2 (10 subjects per list).

3.1.1. Experiment 1. This experiment consisted of a rating task. Subjects read pairs of sentences like (30) on the computer screen, pressing "Next" after each sentence:

(30) John can almost swim. [press NEXT] Therefore he's afraid of drowning.

After each pair of sentences, felicity judgments were elicited with the sentence How reasonable was this sequence? In order to rate the sequence, subjects were presented a numeric scale from 1 ("completely unreasonable") to 5 ("completely reasonable"). The four conditions in the experiment are presented in Table 1; each condition corresponds to a type of continuation, targeting either the proximal or the polar component:

Table 1. Conditions in Experiment 1

\begin{tabular}{lll}
\hline John can almost swim. & $\begin{array}{l}\text { Therefore he'll enjoy a day } \\
\text { at the pool with his friends. } \\
\text { [Proximal] }\end{array}$ & $\begin{array}{l}\text { Therefore he's afraid of drowning. } \\
\text { [Polar] }\end{array}$ \\
John can barely swim. & $\begin{array}{l}\text { Therefore he's afraid of } \\
\text { drowning. [Proximal] }\end{array}$ & $\begin{array}{l}\text { Therefore he'll enjoy a day at the } \\
\text { pool with his friends. [Polar] }\end{array}$ \\
\hline
\end{tabular}

In this experiment, the dependent variable was the rating value attributed to each pair of sentences. The independent variables were the adverb in the first sentence of the pair (almost or barely) and the type of continuation (coherent with the proximal component or coherent with the polar component of the adverb in the first sentence). The second sentence in each pair was introduced by a connective (therefore, so, consequently, it's 


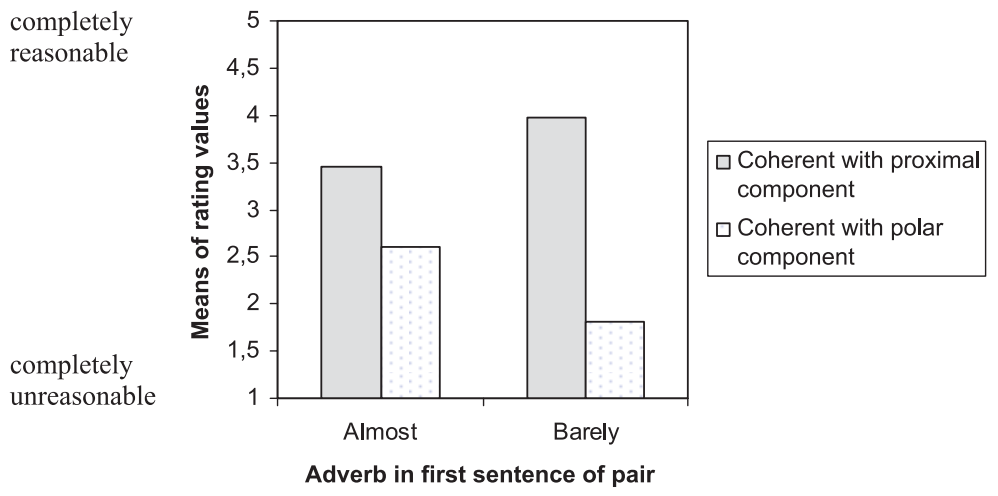

Figure 1. Ratings according to type of continuation

because); the number of tokens of the four connectives was kept the same across all the lists (22 tokens of each connective per list, same number of tokens of each connective in the critical items).

The predictions for this experiment were the following: (i) for both adverbs, continuations coherent with the proximal component (i.e., the asserted content contributed by the adverb) were predicted to obtain higher rating values than continuations coherent with the polar component, and (ii) accordingly, for almost, continuations coherent with the truth of the modified predicate were predicted to be rated higher than continuations coherent with the falsity of the predicate, and the reverse results were predicted for barely.

Both predictions were borne out. The overall ratings by condition graphed in Figure 1 show that one factor clearly has a consistent effect on the results, namely the type of continuation. For both adverbs, subjects provided higher ratings for continuations that were coherent with the proximal component than for continuations coherent with the polar component. Furthermore, there is an interaction between adverb and type of continuation; continuations coherent with the proximal component are rated higher for pairs containing barely than for pairs containing almost, and continuations coherent with the polar component are rated lower for barely than for almost.

The ratings of the judgment task were treated using an analysis of variance. The means of rating values were subjected to a 2 (adverb: almost, barely) $\times 2$ (continuation type: coherent with polar component or coherent with proximal component) repeated measures ANOVA, once by subjects and once by items. Adverb and continuation type were treated as within-subjects variables, and list (subject analysis) and group (item analysis) were treated as between-subjects variables. 
The results demonstrated a significant main effect of the type of continuation $(\mathrm{F} 1[1,44]=369.850, \mathrm{p}<.01, \mathrm{~F} 2[1,16]=195.532, \mathrm{p}<.01)$ and a significant interaction between adverb and type of continuation $(\mathrm{F} 1[1,44]=63.367, \mathrm{p}<.01, \mathrm{~F} 2[1,16]=37.223, \mathrm{p}<.01)$. Post-hoc pairedsamples $t$-tests, at a Bonferroni corrected level of $\mathrm{p}<.008$, revealed the nature of the interaction. The ratings of continuations coherent with the proximal component are higher for barely than for almost $(\mathrm{t}[47]=$ $-3.846, \mathrm{p}<.0005$ ), and the ratings of continuations coherent with the polar component are lower for barely than for almost $(\mathrm{t}[47]=7.855$, $\mathrm{p}<.0005)$. Furthermore, with the same number of observations for the two adverbs, the difference between the ratings of the two continuations is greater for barely $(\mathrm{t}[47]=-18.253, \mathrm{p}<.0005)$ than for almost $(\mathrm{t}[47]=-6.692, \mathrm{p}<.0005)$. Although both are significant at $\mathrm{p}<.008$, the relative size of the $t$-values suggests that the effect is greater for barely than for almost.

Other effects included an interaction with list (the adverb $\times$ type of continuation interaction differed across lists: $\mathrm{F} 1[3,44]=5.150, \mathrm{p}<.01)$, and a marginal effect of adverb in the subject analysis $(\mathrm{F} 1[1,44]=3.087$, $\mathrm{p}=.086)$ that is not significant in the item analysis. In the item analysis, group has a significant main effect $(\mathrm{F} 2[1,16]=3.652, \mathrm{p}<.05)$.

3.1.2. Experiment 2. In this experiment, subjects were directly asked about the truth conditions of sentences containing AAs. They were requested to provide a True/False judgment about a sentence containing either almost or barely, presented on the computer screen, according to the sequence exemplified in (31):

John can almost swim. [press NEXT] John can swim. T or F?

The four conditions in this experiment are presented in Table 2, where "Sentence 2" corresponds to the propositional component which is being inquired about (this factor will henceforth be called "component"). The third column gives the name of the component for each adverb, following the terminology of the Conjunctive Analysis. This column groups the

Table 2. Conditions in Experiment 2

\begin{tabular}{llll}
\hline Sentence 1 & Sentence 2 & Targeted component & Condition name \\
\hline John can almost swim. & John can swim. & Proximal & A can \\
John can almost swim. & John cannot swim. & Polar & A cannot \\
John can barely swim. & John can swim. & Polar & B can \\
John can barely swim. & John cannot swim. & Proximal & B cannot \\
\hline
\end{tabular}


conditions for the two adverbs according to the component that was the target of the question. In the fourth column, A stands for almost and B stands for barely.

The dependent variables were the True/False judgments elicited from the subjects and the response time (RT) of the judgment decision. The independent variables were the adverb in Sentence 1 (almost or barely) and the positive or negative sentence, containing can or cannot, presented after the sentence with the AA. The set of filler items contained the same number of items for each possible response in each condition, i.e., out of the 68 fillers, there were 17 "True" responses for can, 17 "False" responses for can, 17 "True" responses for cannot, and 17 "False" responses for cannot.

The predictions for this experiment were the following. Given that the task of the present experiment directly targeted the entailments of sentences containing an AA, the True/False judgments were predicted to reflect the entailment patterns described by the Conjunctive Analysis, which are not disputed in the present paper. Therefore, subjects were expected to respond in accordance with the polar component (which pertains to the truth or falsity of the modified predicate in the world of evaluation).

In order to make the implications of the results clearer, the predictions of two possible hypotheses are fleshed out in the charts below. In Table 3, Hypothesis 1 is schematically presented; if subjects respond in accordance with the polar component, the higher percentages of True/False judgments should be distributed according to the following pattern (here, exemplified with the predicate can swim):

Table 3. Hypothesis 1 (subjects respond in accordance with the polar component)

\begin{tabular}{lll}
\hline & John can swim & John cannot swim \\
\hline John can almost swim. & $\mathrm{F}$ & $\mathrm{T}$ \\
John can barely swim. & $\mathrm{T}$ & $\mathrm{F}$ \\
\hline
\end{tabular}

On the other hand, if subjects respond in accordance with the proximal component (Hypothesis 2, given in Table 4), the inverse results are expected, i.e., higher percentages of "True" responses would be expected in the cases in which the second sentence corresponds to the polarity of the respective proximal component of the AA and higher percentages of "False" responses would be expected when the second sentence corresponds to the polar component: 
Table 4. Hypothesis 2 (subjects respond in accordance with the proximal component)

\begin{tabular}{lll}
\hline & John can swim & John cannot swim \\
\hline John can almost swim. & T & F \\
John can barely swim. & F & T \\
\hline
\end{tabular}

As for the second dependent variable, it is not possible to predict differences in RTs for True/False responses since the lexical material is not the same in each case. The problems pertaining to the analysis of the results of RTs will be discussed below.

To sum up, in this experiment subjects were specifically asked about the truth conditions of sentences containing AAs, and each condition targeted each of the entailments of the two adverbs.

The results, graphed in Figure 2, make apparent a general pattern; for both adverbs, the majority of the responses are in accordance with the polar component, i.e., in support of Hypothesis 1 (see Table 3). This can be seen clearly by comparing the conditions targeting the polar component in Table 2 and the two middle columns in Figure 2, representing the higher proportions of "True" responses per subject. The data show that component had a main effect on the results, and, as in Experiment 1 , there is an interaction, here between adverb and component. This interaction involves a difference between the two adverbs: the proportion of "True" responses was higher for barely than for almost both when the target was the polar component and when it was the proximal component.

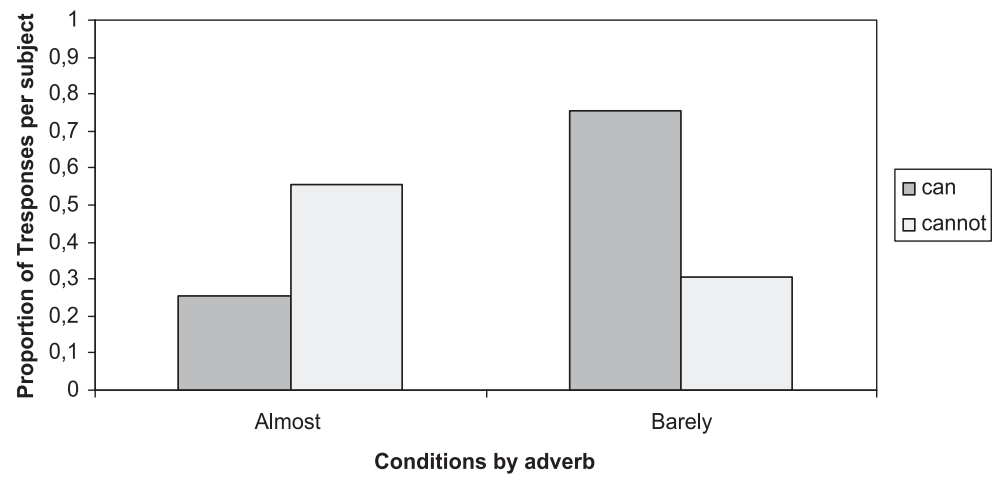

Figure 2. Proportion of 'true' responses per subject per condition (means) 
On a closer look, one can see that only the results obtained for barely support Hypothesis 1 ( 0.755 of "True" responses for "John can swim", 0.305 of "True" responses for "John cannot swim"). In fact, even if the higher proportion of "True" responses pertaining to the sentences with almost is for "John cannot swim" (i.e., the polar component), the results show almost a half/half split between "True" and "False" responses for this component ( 0.555 for "True" and 0.445 for "False").

The True/False judgments were analyzed in the following way. A 2 (adverb: almost, barely) $\times 2$ (component: polar or proximal) repeatedmeasures ANOVA was run on arcsine-transformed proportions of "True" responses per subject and per item per condition. Again, adverb and component were treated as within-subjects variables, and list was treated as a between-subjects variable. The results demonstrated a significant effect of the interaction adverb $\times$ component $(F 1[1,36]=36.126$, $\mathrm{p}<.01, \mathrm{~F} 2[1,16]=171,615, \mathrm{p}<.01)$. The analysis also showed a significant main effect of adverb $(\mathrm{F} 1[1,36]=45.294, \mathrm{p}<.01, \mathrm{~F} 2[1,16]=$ $53,826, \mathrm{p}<.01)$, and a significant main effect of component $(\mathrm{F} 1[1,36]=$ $5.041, \mathrm{p}<.05)$, qualified by the referred interaction.

As for the reaction time (RT) data, a caveat should be mentioned. Given that the lexical material and the response type ( $\mathrm{T}$ vs. F) are not the same across the different conditions, the comparisons between the RT reported should be made with caution. For example, one cannot compare a "True" response to an item in the "Acan" condition to a "True" response in the "Bcannot" condition; besides the different adverb, this would mean comparing a "True" response to a positive sentence and to a negative sentence. However, if we keep the type of sentence constant and vary only the response type, and look at the condition that inquired directly about the polar component of almost, it is interesting to note that this condition presents delayed reaction times: the mean RT for "A cannot" with "True" as response was $1751.73 \mathrm{~ms}$ and the mean RT for "A cannot" with "False" as response was $1495.16 \mathrm{~ms}$.

\section{Discussion of the results}

The results of the two experiments conducted provide robust psycholinguistic evidence for the asymmetry of the meaning components of AAs almost and barely. The results of the first experiment show that subjects treat sentences that are coherent with the proximal component of the AA as felicitous continuations of a sentence containing the adverb, and treat sentences that are coherent with the polar component as infelicitous continuations. These results demonstrate that the two propositional 
components have a different bearing on textual coherence. As for the second experiment, it shows that subjects respond according to the polar component when asked to provide a truth-conditional judgment about the meaning of the sentence in isolation.

This evidence is not conclusive as to the theoretical status of the polar component, but the data from the second experiment suggest that it should be considered part of the conventional content of the adverb. Hence, combined with other sources of evidence for the behavior displayed by AAs (among which the tests discussed in Section 2.1), the results obtained seem to argue against the conversational implicature approach.

Focusing now on the results of each experiment considered separately, the first experiment showed that the difference between the ratings for each component was greater for barely than for almost. This suggests that subjects have more polarized intuitions about the felicity of continuations with respect to sentences containing barely than with respect to sentences containing almost. A possible reason for this difference is the fact that barely displays a negative behavior, as said in Section 2 and argued by Klein (1998), Sevi (1998) and Horn (2002). Huddleston and Pullum (2002) group together few, barely and little as "quasi-negatives". 9 Interestingly, studies on language acquisition show that the negative orientation of barely is prevalent in judgments of children at least as young as 6 years old (Champaud and Bassano 1987).

However, these studies do not specify to what extent barely is negative - note that according to (3) above, both almost and barely contribute the conjunction of a positive and a negative proposition. What seems to be crucial, though, is that the "negative" contribution of barely (the orientation toward $\sim p$ ) is associated with the proximal component, i.e., the asserted component, as shown by the results of the present study.

As for the second experiment, the results of the True/False judgment task supported Hypothesis 1, i.e., when asked about the truth conditions of a sentence containing an $\mathrm{AA}$, subjects responded in accordance with the polar component. However, what is more striking about the data is that when the targeted component was the polar component in sentences containing almost, the percentages obtained were $55.5 \%$ True and $44.5 \%$ False. This suggests that, contrary to barely, in sentences with almost native speakers do not have clear judgments pertaining to the commitment to the truth or falsity of the modified predicate in the actual world, despite the general tendency which confirms Hypothesis 1. The results point to an interpretation of almost as denoting a general notion of approximation ('more or less'), at least when almost modifies the predicates tested in this study. The decision about the polar component may be more closely 
related with the semantics of the modified predicate in sentences with almost than in sentences with barely, ${ }^{10}$ and depend on whether the meaning of the predicate provides a clear-cut distinction between two states of affairs of opposite polarity (Hitzeman 1992; Amaral 2007), like missing or not missing a train in the examples above. This suggests that separate analyses are required for the two adverbs (which eventually must account for the cases in which the truth conditions given in (3) seem intuitively adequate).

Furthermore, these data provide evidence against the analysis of almost and barely as inner negations of each other, as argued for by the proponents of the Conjunctive Analysis. If this were the case, one would predict symmetric results both in the rating and in the True/False judgment tasks. A possible objection to this line of reasoning is that barely contributes a negative implication, and hence is potentially harder to process (cf. Horn 1989), not allowing for a comparison with the results obtained with the sentences containing almost (Henk Zeevat, p.c.). ${ }^{11}$ However, as pointed out above, as long as we assume, with the Conjunctive Analysis, that both adverbs contribute the conjunction of a negative and a positive assertion, this objection does not hold; the crucial point that remains to be answered is in what respect barely is negative.

While a semantic account of almost and barely is beyond the scope of this paper, the experimental evidence reported suggests ways to improve the Conjunctive Analysis in (3). In order to adequately capture the semantic behavior of AAs, it seems necessary to provide a more finegrained account of their meaning components, in particular of the proximal component, and to take into consideration how the information they contribute interacts with context update.

\section{Conclusions}

The interpretation of almost and barely provides an interesting case to study the multiple implications contributed by a lexical item to the meaning of a sentence, given the opposite polarity of the two conjuncts that each adverb contributes.

Past research on AAs has focused on the classification of each component, according to the standard tests for different kinds of implications. Although this is an important step in teasing apart the different meaning components of AAs, the present study tries to show that this type of analysis falls short of fully exploring the contribution of multiple implications by a lexical item to the meaning of a sentence. 
This study makes a novel contribution to the discussion of the interpretation of AAs in that, along the lines of Horn's proposal, it points to a pragmatic difference in the role of each meaning component of AAs. In particular, this study provides psycholinguistic evidence for the different behavior of each entailment of an AA and for the interplay between asserted content and textual coherence. In other words, the different tasks presented to native speakers show that implications which are conventionally associated with a certain linguistic form interact in different ways with the context of use of a sentence and thus have different bearings on textual coherence.

The ultimate question raised by the analysis of these adverbs is the relation between the two propositional components that they contribute. A relevant question at this point is what exactly does it mean to be "assertorically inert", i.e., why is it the case that one of the entailments contributed by AAs is a conventional aspect of the meaning of the lexical item but does not update the conversational record, albeit contributing to the determination of the truth conditions of the sentence. A reasonable hypothesis is that the two meaning components of AAs are related and the polar component is conceptually entailed by the information contributed by AAs that updates the context set, i.e., by the proximal component. But this is certainly the topic for another paper.

Received 28 August 2007

University of Liverpool

Revised version received

2 October 2008

\section{Notes}

* I would like to thank Allison Blodgett, Kathleen Hall, Larry Horn, Dongmei Li, Gilberto Loureiro, Lino Mioni, Janina Radó, Craige Roberts, Sharon Ross, Scott Schwenter and Shari Speer for their contribution at several stages of the research presented here. This research was possible due to the generous support of Fundação Calouste Gulbenkian (BD 50201). I would also like to thank the two anonymous reviewers of Linguistics for their insightful comments, as well as the participants of "Linguistic Evidence" (Tübingen, February 2-4, 2006) and "SPRIK" (University of Oslo, June $8-11,2006)$ conferences, where parts of this research were presented. Any remaining mistakes are, of course, my own responsibility. Correspondence address: School of Languages, Cultures and Area Studies, University of Liverpool, Cypress Building, Chatham Street, Liverpool L69 7ZR, United Kingdom. E-mail: pamaral@liverpool. ac.uk.

1. The orientation towards a positive or a negative state of affairs as part of the meaning of AAs is reminiscent of the perspective contributed by "phrasal adverbials" in the aspectual domain (cf. Löbner 1989; van der Auwera 1998; Smessaert 2007). The aspec- 
tual meaning of phrasal adverbials interacts in a constrained way with evaluative information (see Smessaert 2007). One of the reviewers pointed out that AAs have an evaluative dimension that is independent from the two meaning components. Whereas I agree that AAs may also contribute evaluative information, I believe that this dimension cannot be separated from the scalar semantics of the adverbs (see Penka 2005; Amaral 2007 for a detailed analysis), as part of their proximal component. However, such an argument is beyond the scope of this paper.

2. As pointed out by a reviewer, the lexical meaning of the verb miss is negative in itself (not catch), but the structure of the polarity transition is not affected by this fact. The underlying polar switch to which the proximal component makes reference relates to the polarity sensitivity displayed by AAs crosslinguistically (cf. van der Wouden 1997; Pons Bordería and Schwenter 2005; Amaral 2007).

3. The use of capitals is intended to signal prosodic prominence.

4. According to Anscombre and Ducrot, two propositions $\mathrm{p}_{1}$ and $\mathrm{p}_{2}$ are placed on the same argumentative scale if they can constitute arguments, or premises, for a third proposition q. This relation between an argument and its plausible conclusion is not a relation of logical implication, but rather a relation supported by a typical correlation provided by world knowledge.

5. I am indebted to one of the anonymous reviewers, who brought this point to my attention.

6. These experiments compared the interpretation of the counterparts of almost and only in Finnish, Danish (Lundquist and Jarvella 1994) and French (Jarvella and Lundquist 1994). These studies do not address the relation between the meaning of almost and barely. The examples provided are from Lundquist and Jarvella (1994: 39).

7. Examples (22) through (25) are from Moxey and Sanford (1998: 734).

8. The complete list of materials is available upon request.

9. Another source of evidence for the similarity of barely with negative adverbials, which is noted by Horn, is the fact that, unlike almost, it can be fronted, triggering subject inversion, as in (i); the same holds for hardly, as shown in (ii), from Horn (2002: 57). Crucially, there is crosslinguistic evidence for a similar behavior in translation equivalents to barely (see Amaral 2007):

(i) $\{$ Barely/*Almost $\}$ had we arrived when an unearthly scream rang out.

(ii) Hardly ever will you see such a thing.

10. Champaud and Bassano (1987) report similar results for their experiment with presque and $a$ peine.

11. A possible follow-up of this study with the purpose of addressing this issue would be a repetition of the two experiments described, this time using almost not and barely. Future work on the negative character of barely could consist of memory experiments using recall tasks (cf. Moxey and Sanford 1993); it would be illuminating to test whether erroneous recalls of sentences containing barely tend to associate with the proximal component, i.e., with the negative propositional component.

\section{References}

Amaral, Patrícia. 2007. The meaning of approximative adverbs: Evidence from European Portuguese. Columbus, $\mathrm{OH}$ : The Ohio State University dissertation. 
Anscombre, Jean-Claude \& Oswald Ducrot. 1983. L'Argumentation dans la langue. Brussels: Mardaga.

van der Auwera, Johan. 1998. Phasal adverbials in the languages of Europe. In Johan van der Auwera \& Dónall P. Ó Baoill (eds.), Adverbial constructions in the languages of Europe, 25-145. Berlin \& New York: Mouton de Gruyter.

Champaud, Christian \& Dominique Bassano. 1987. Argumentative and informative functions of French intensity modifiers "presque" (almost), "à peine" (just, barely) and "à peu près" (about): An experimental study of children and adults. Cahiers de Psychologie Cognitive/European Bulletin of Cognitive Psychology 7(6). 605-631.

Ducrot, Oswald. 1972. Dire et ne pas dire. Paris: Hermann.

Fillmore, Charles, Paul Kay \& Mary Catherine O'Connor. 1988. Regularity and idiomaticity in grammatical constructions: The case of let alone. Language 64. 501-538.

Hitzeman, Janet. 1992. The selectional properties and entailments of "almost". Papers from the 28th Annual Meeting of the Chicago Linguistics Society. 225-238.

Horn, Laurence R. 1985. Metalinguistic negation and pragmatic ambiguity. Language 61. $121-174$.

Horn, Laurence R. 1989. A natural history of negation. Chicago: University of Chicago Press.

Horn, Laurence R. 2002. Assertoric inertia and NPI licensing. Proceedings of the 38th Annual Meeting of the Chicago Linguistics Society: Parasession on Negation and Polarity 38(2). 55-82.

Huddleston, Rodney \& Geoffrey K. Pullum. 2002. The Cambridge grammar of the English language. Cambridge: Cambridge University Press.

Jarvella, Robert J. \& Lita Lundquist. 1994. Scales in the interpretation of words, sentences, and texts. Journal of Semantics 10. 171-198.

Kadmon, Nirit. 2001. Formal pragmatics: Semantics, pragmatics, presupposition, and focus. Malden, MA \& Oxford, UK: Blackwell.

Kay, Paul. 1990. Even. Linguistics and Philosophy 13. 59-111.

Klein, Henny. 1998. Adverbs of degree in Dutch and related languages. Amsterdam \& Philadelphia: John Benjamins.

König, Ekkehard. 1991. The meaning of focus particles: A comparative perspective. London: Routledge.

Li, Charles N. 1976. A functional explanation for an unexpected case of ambiguity (S or $\sim$ S). In Andrew M. Devine \& Laurence D. Stephens (eds.), Linguistic studies offered to Joseph Greenberg, vol. 3, 527-535. Saratoga, CA: Anma Libri and Co..

Löbner, Sebastian. 1989. German schon-erst-noch: An integrated analysis. Linguistics and Philosophy 12. 167-212.

Lundquist, Lita \& Robert J. Jarvella. 1994. Ups and downs in scalar inferences. Journal of Semantics 11. 33-53.

Moxey, Linda M. \& Anthony J. Sanford. 1993. Communicating quantities: A psychological perspective. Hillsdale, NJ: Lawrence Erlbaum.

Moxey, Linda M. \& Anthony J. Sanford. 1998. Complement set reference and quantifiers. Proceedings of the 20th Annual Conference of the Cognitive Science Society: August 1-4, 1998, University of Wisconsin-Madison, 734-739. London: Lawrence Erlbaum.

Nouwen, Rick. 2006. Remarks on the polar orientation of almost. In Jeroen van de Weijer \& Bettelou Los (eds.), Linguistics in the Netherlands, 162-173. Amsterdam \& Philadelphia: John Benjamins.

Paterson, Kevin B., Anthony J. Sanford, Linda M. Moxey \& Eugene Dawydiak. 1998. Quantifier polarity and referential focus during reading. Journal of Memory and Language 39. 290-306. 
Penka, Doris. 2005. "Almost”: A test? In Paul Dekker \& Michael Franke (eds.), Proceedings of the 15th Amsterdam Colloquium. Amsterdam: Institute for Logic, Language \& Computation, University of Amsterdam.

Pons Bordería, Salvador \& Scott A. Schwenter. 2005. Polar meaning and "expletive" negation in approximative adverbs: Spanish por poco (no). Journal of Historical Pragmatics 6(2). 262-282.

Rapp, Irene \& Arnim von Stechow. 1999. Fast 'almost' and the visibility parameter for functional adverbs. Journal of Semantics 16. 149-204.

Roberts, Craige. Submitted. Only, presupposition and implicature. Unpublished ms., The Ohio State University.

Sadock, Jerrold M. 1981. Almost. In Peter Cole (ed.), Radical pragmatics, 257-271. New York: Academic Press.

Schwenter, Scott A. 2002. Discourse context and polysemy: Spanish casi. In Caroline R. Wilshire \& Joaquim Camps (eds.), Romance phonology and variation: Selected papers from the 30th Linguistic Symposium on Romance Languages, Gainesville, Florida, February 2000, 161-175. Amsterdam \& Philadelphia: John Benjamins.

Sevi, Aldo. 1998. A semantics for almost and barely. Tel-Aviv: Tel-Aviv University M.A. thesis.

Smessaert, Hans. 2007. The evaluation of aspectual distance, speed and progress. In Louis de Saussure, Jacques Moeschler \& Genoveva Puskas (eds.), Cahiers Chronos 17: Tense, mood and aspect: Theoretical and descriptive issues: Proceedings of the 6th Chronos conference, Université de Genève, September 22-24, 2004, 27-45. Amsterdam: Rodopi.

Stalnaker, Robert C. 1978. Assertion. In Peter Cole (ed.), Syntax and Semantics 9: Pragmatics, 315-332. New York: Academic Press.

van der Wouden, Ton. 1997. Negative contexts. Collocation, polarity and multiple negation. New York: Routledge.

Ziegeler, Debra. 2000. What almost can reveal about counterfactual inferences. Journal of Pragmatics 32. 1743-1776. 